\title{
Understanding Participation rates in post-16 Mathematics And Physics: Conceptualising and operationalising the UPMAP Project
}

Running head: Participation rates in post-16 Mathematics And Physics

Authors: Michael Reiss, Celia Hoyles, Tamjid Mujtaba, Bijan Riazi-Farzad, Melissa Rodd, Shirley Simon, Fani Stylianidou

Affiliation: Institute of Education, University of London

Address: 20 Bedford Way, London WC1H OAL, UK

\section{Abstract}

We report on a project currently in progress that aims to identify through research the range of factors (individual, school and out-of-school, including home) and their interactions that influence post-16 (i.e. post-compulsory) participation in mathematics and physics in the UK and to assess their relative importance among different student populations. In this project we are beginning to elucidate the views of students and examine the sources of these views by exploring the contexts in which both school and university students experience barriers or opportunities and form their identities with regard to participation in mathematics and physics. Our focus in this paper is on our methodology, the reasons for it and how and why our approach to data collection developed during the project. We situate our work within a mixed methods approach, using multilevel modelling and discourse analysis to analyse and interpret our findings that derive from our own questionnaires, interviews and ethnography and from existing large-scale datasets. We argue that greater acknowledgement in the education literatures that investigate student participation in mathematics and science needs to be made than is usual of the range of factors, including unconscious forces, that may affect participation.

Key words: choice, defences, mathematics, mixed methods, multilevel modelling, participation, physics, school factors, unconscious forces 


\section{Background and framing}

Worldwide, there is still a shortage of studies in mathematics and science education that examine student engagement over time and research the reasons for the take up or non take up of mathematics and science at the point at which these subjects become optional. Much remains to be done to understand what determines student attitudes towards mathematics and science (Osborne et al., 2003; Lord \& Jones, 2006) and what drives student subject choice once subjects become optional (Blenkinsop et al., 2006; QCA Research Faculty, 2007; Gill et al., 2009). Of the sciences, we concentrate on physics. In part this is because of the severity of the problems: both in the UK and in a number of other countries these include a persistent shortage of specialist physics teachers and a continuing decline in the percentage of the school cohort that chooses to study physics 'post-16' (a term that we use as a shorthand for 'post-compulsory'). In part this is because of the historically (many would argue contingently) close links between physics and mathematics (cf. Carson, 1999). At the same time, there may well be differences between physics and mathematics, for instance with regards to extrinsic reasons for participation - with mathematics being regarded as having greater general 'exchange value' regardless of career or university choice (cf. Williams, 2008) - and how these reasons are interpreted by family, friends and parents.

When students encounter school mathematics and physics, they respond to them in a variety of ways. Understanding the reasons for these varied responses may help make sense of the particularities of how different students react to mathematics and physics and of the phenomenon, widely found in industrialised countries, in which many of those who do well at school in mathematics and the sciences reject them (Nardi \& Steward, 2003; Schreiner, 2006).

In this project, school subjects are conceptualised as special types of discourses (Harré \& Gillett, 1995; Sfard \& Prusak, 2005; Mendick, 2006). Part of our work, therefore, is grounded in a different language from that generally 
used in the analysis of 'the problem of uptake in mathematics and physics', and wider, social and cultural forces are considered as well as individual issues to do with understanding and affect. We are open to a framing in which students respond to curricula, to pedagogies and to subject representations outside of schools (e.g. in films and magazines, on TV, in everyday conversations) by partial negotiations, both of themselves and of mathematics / physics; in other words, by reconceptualising both themselves and these subjects. Such an approach fits with the presumption that once students are no longer required to do certain subjects, participation in such subjects depends at least in part on how students see both themselves and the subjects. Neither of these is fixed. Each can shift as a result of experiences both inside and outside the classroom (Black et al., 2009).

This identification with the meaningfulness of mathematics / physics is partly the result of such cultural forces but it is the individual's affective response, both conscious and unconscious, that ultimately attracts, or fails to attract, each person to the subject (Reiss, 2005; Brown et al., 2008; Boaler, 2009). Unless there is sufficient positive connect between a student's developing sense of self and the meanings they find in mathematics / physics, the student-subject relationship may not flourish but atrophy or become one of antagonism. Of course, such individual factors do not operate in isolation from other factors, for example those operating at the level of schools or society more generally. The methodology for our project is therefore designed to help us investigate and, so far as possible, untangle the relationships between the various factors operating at various levels.

\section{Methodology}

Our study comprises three strands. As described below, these strands are designed to interrelate and feed into one another either directly (the same students feature in Strands 1 and 2) or indirectly (Strand 3 examines issues that some Strand 1 and Strand 2 students will face in the future). Our expectation is that over the three years of the project, the three strands will collectively help us the better to answer our central research question: "Why 
do certain students, but not others, choose to continue with their formal studies in mathematics and/or physics post-16?'.

\section{Strand 1: Mapping trajectories of engagement and disenchantment}

In Strand 1, 'Mapping trajectories of engagement and disenchantment', the intention was to obtain a sample of schools across the UK that would agree to work with us by having year 8 and year 10 students complete a student questionnaire about themselves, their conceptual understanding of mathematics / physics and their views of the subject. In all, we aimed to obtain 20,000 student questionnaires and then to obtain a second questionnaire from as many of these students as possible two years later. Formal calculations of anticipated effect sizes / statistical power were not undertaken owing to the uncertainty as to how large a number of students would be captured on both occasions. The figure of 20,000 was therefore chosen partly because it is reasonably typical of other successful UK longitudinal studies (Institute For Social \& Economic Research, 2010) and partly because it was the most we could afford.

Whilst there is abundant literature pertaining to extrinsic factors affecting choices and achievement, comparatively little has been reported on the relationship between intrinsic factors, such as personality and attitudes to, and achievement in, mathematics and science and their relationships to subject choice, achievement and post-16 participation. Accordingly, we designed student questionnaires to include items from established psychological constructs alongside validated subject-specific conceptual tasks so that possible relationships between performance, confidence and intrinsic and extrinsic factors could be explored in each subject and across the two subjects. Mindful of criticisms (e.g. Blalock et al., 2008) that science attitude surveys typically possess weak psychometric properties, a high proportion of the items for the student questionnaire were taken from well-validated constructs in the literature that it seemed reasonable to hypothesise might be related to participation / intention to participate in mathematics and/or physics post-16. 
We anticipated finding a wide degree of variation in policies and procedures and human and material resources, both between schools and between mathematics and physics / science departments within schools. Accordingly, we developed two further questionnaires (school questionnaires) one to be completed by a senior teacher in the mathematics department; the other by a senior teacher in the science/physics department.

During the first six months of the project we developed our instruments for Strand 1 and recruited schools. We had originally intended to recruit 200 schools, principally using data provided by the DCSF (Department for Children, Schools and Families). In the end, 210 schools agreed to participate (out of slightly over 1000 approached, i.e. about one-quarter of the secondary schools in the UK), 141 of which subsequently returned student questionnaires. In a handful of cases schools decided that some of the questions, e.g. about parental occupation or details of home circumstances, were too intrusive. In the great majority of cases though where schools did not return student questionnaires, even though they had agreed to, it was simply that the practicalities of school life took precedence. However, we were able to compensate to some extent by getting those schools that did participate to return more questionnaires than we had originally expected (an average of about 160 per school rather than 100 ) so that we managed to collect 23,000 completed student questionnaires instead of the 20,000 for which we had been aiming.

The student questionnaires went though about five rounds of design and piloting and we ended up with four versions: one for year 8 students (12-13 year-olds) and focusing on mathematics; one for year 8 students and focusing on physics; ne for year 10 (14-15 year-olds) students and focusing on mathematics; one for year 10 students and focusing on physics. The findings from successive rounds of piloting meant that a number of the items were reworded so as to make them easier to understand for these age ranges. In addition, we included a number of items in our piloting (e.g. use by students of new digital technologies) because we thought it reasonable to presume that there might be a causal relationship between them and participation / intention to participate and certain items within constructs were omitted or re-worded. 
The result was that all constructs in the final versions of the questionnaires had Cronbach alphas of between 0.6 and 0.9 . Subsequently, we ran confirmatory factor analyses which confirmed the great majority of the constructs but also led to some changes (e.g. a redistribution of certain items between the constructs 'attitudes to lessons' and 'perceptions of lessons').

The final questionnaires can downloaded from the project website (UPMAP, 2009). The structure of all four student questionnaires is the same and while there is considerable overlap between the two questionnaires within each year group, we told schools that it would be useful to us if at least some students in year 8 and some in year 10 completed both questionnaires for their respective year groups. (This will allow us both to compare, within individuals, responses to the mathematics and physics items and also enable us to see to what extent the same questions - i.e. ones that are not specific to mathematics or to physics - elicit identical answers on both occasions.)

Each of the four student questionnaires is divided into the following 14 sections:

1. About You (13 questions including name, gender, date of birth, number of different mathematics / science teachers they have had, parental occupation).

2. More About You (15 questions on a five-point scale from 'Not at all' to 'More than once a week' about the frequency with which the student takes part in a range of activities including sports, arts and music, religious activities, youth centres / clubs, mathematics / physics clubs, master classes, competitions and outings).

3. Your Future Studies (three questions, mostly open-ended, about what the student might intend studying, if anything, after the age of 16 and why).

4. About Studying Mathematics [Physics, for the physics questionnaires] (nine statements to be answered on a six-point scale from Strongly Agree to Strongly Disagree with the option of Can't Say, e.g. 'I think maths is a useful subject', 'I am good at maths' and 'My friends think I 
should continue with maths after my GCSEs' [GCSEs are the examinations taken by almost all 16 year-olds in England, Northern Ireland and Wales; throughout the questionnaires, appropriate changes were made for Scotland, and, less often, for Northern Ireland and Wales when there were differences from the situation in England]).

5. My Views on Mathematics [or Physics] (begins with an open-ended question 'Please tell us what you think mathematics is about' [the Physics version has two such questions: 'Please tell us what you think science is about' and 'Please tell us what you think physics is about'] and then has 12 statements to be answered on a six-point scale from Strongly Agree to Strongly Disagree with the option of Can't Say, e.g. 'People who are good at maths [physics] get well-paid jobs', 'Maths [Physics] improves your social skills' and 'These days, everybody needs to know some maths [physics]' and concludes with an openended question 'Can you think of any experiences, such as a book you read, a film you saw, a place you visited or a person you met or know, that may have changed the way you view mathematics [physics]? If yes, please explain').

6. Your Mathematics [Physics] Lessons (begins with 14 statements to be answered on a six-point scale from Strongly Agree to Strongly Disagree with the option of Can't Say, e.g. 'In my maths [physics] lessons, I have the opportunity to discuss my mathematical ideas [ideas about physics]' and then has one question to be answered on a five-point scale from Near top to Near bottom, namely 'Thinking about your maths [physics] lessons, how do you feel you compare with the others in your group?').

7. Your Mathematics [Physics] Teacher (13 statements to be answered on a six-point scale from Strongly Agree to Strongly Disagree with the option of Can't Say, e.g. 'My maths [physics] teacher has high expectations of what the students can learn', 'My maths [physics] teacher believes that mistakes are OK as long as we are learning' and 'My maths [physics] teacher marks and returns homework quickly'). 
8. Help With Mathematics [Physics] (ten statements to be answered on a six-point scale from Strongly Agree to Strongly Disagree, e.g. 'I do extra maths [physics] at home (i.e. work not set by teachers)' and 'Someone in my family helps me with my maths [physics] work').

9. More About You (12 statements to be answered on a six-point scale from Strongly Agree to Strongly Disagree with the option of Can't Say, e.g. 'I enjoy strategy games (e.g. Chess, battleships, Sudoku)', 'I have organised collections (e.g. music files, photos, Pokemon cards)', 'I like to interact with people online' and 'I like to solve problems').

10. My School (nine statements to be answered on a six-point scale from Strongly Agree to Strongly Disagree with the option of Can't Say, e.g. 'It is important for me to know how well I am doing at school', 'Adults in this school seem to listen to students' concerns' and 'I can be myself at this school').

11. Your Family's Views (13 statements to be answered on a six-point scale from Strongly Agree to Strongly Disagree with the option of Can't Say, e.g. 'My parents / carers understand me' and 'If my general standard of maths [physics] work slipped, my family would take away privileges or ground me').

12. Other People and You (16 statements to be answered on a six-point scale from Strongly Agree to Strongly Disagree with the option of Can't Say, e.g. 'I start conversations easily', 'Teamwork is really more important than who wins' and 'I don't trust very many people').

13. Your Everyday Life (13 statements to be answered on a six-point scale from Strongly Agree to Strongly Disagree with the option of Can't Say, e.g. 'I like to think up new ideas', 'When I get what I want, it's usually because I worked hard for it' and 'I worry about a lot of things').

14. Mathematics [Physics] Tasks (two conceptual tasks [four shorter ones in physics]. The same mathematics tasks were used for year 8 and for year 10; one of these is given in Figure 1. Some of the physics tasks 
used for year 10 were the same as those used for year 8 and some were different; the two year 10 electricity tasks are given in Figure 2.).

Our second instrument for Strand 1 was a school questionnaire which was produced in two versions - one for a senior teacher in the mathematics department to complete and one for a senior teacher in the physics / science department to complete. Both are available at UPMAP (2009). Each was divided into ten sections:

1. About you.

2. Opportunities for progression (enrichment activities in mathematics [physics] for students).

3. Is your school's capacity to teach mathematics [physics] hindered by any of the following? (e.g. 'A shortage of qualified mathematics [physics] teachers').

4. In your opinion, what are the factors that contribute to the professional satisfaction of teachers of mathematics [physics] in your school?

5. Participation (to do with perceived reasons for student participation in post-16 mathematics / physics).

6. About your school's mathematics [physics] department.

7. Your department's links with outside establishments.

8. Mathematics- [Physics-]related careers.

9. Continuing Professional Development (CPD).

10. Further comments.

We discuss further below (under 'Approaches to analysis') the reasons for the inclusion of the various items in the student and school questionnaires but, in essence, we are trying to gather almost any relevant data that could reliably be obtained with such tools that might allow subsequent statistical associations to be found between our key outputs (student intention to study 
mathematics or physics post-16) and the various inputs. It might be objected that we are therefore setting out on a 'fishing expedition' in which, to switch metaphors, a scatter gun approach is used with the intention of obtaining at least some significant results. We can respond to this criticism in two ways: first of all, we had reasons (the literature, our professional judgement, the preliminary findings from our piloting) to include all our items; secondly, fishing expeditions (and on-one fishes at random) can be defended in a number of ways. When heading into relatively unexplored waters it's unwise to restrict one's nets so that they are capable only of catching a small proportion of the available fish. It's better to use a large net with a fine mesh and then decide which of the caught fish are worth taking to port and which should be thrown back into the sea. Modern genomics is a good example of a science that fishes in this way. Huge amounts of data are gathered that are subsequently analysed and interpreted. To go down a classical route in which a relatively small number of hypotheses are devised in advance of data collection risks prior researcher expectations being allowed to trump what nature has to tell us.

At the same time, although the broad-based approach to the inclusion of items in our questionnaires that we have adopted is typical of many cohort studies (e.g. Centre for Longitudinal Studies, 2010), the inclusion of such a large number of items risks a plethora of statistical tests inevitably finding some to be statistically significant even when little meaning so attaches. The risk of this can be reduced partly by undertaking statistical testing at the level of constructs rather than items, partly by only drawing inferences for correlations found to be significant at the $p<0.01$ rather than $p<0.05$ level and partly by calculating effect sizes.

A second phase of Strand 1 with new student questionnaires for year 10 and year 12 and new school questionnaires is being undertaken. The questions are similar to those in the first phase but we have used our emerging findings from Strand 1 and from Strand 2 to explore both some new areas and some existing areas in more depth. By the time of this second phase of Strand 1, the year 10 students from our first phase are in year 12 or have left education. We will therefore be able to correlate the various inputs obtained from the 
year 10 questionnaires with whether or not individual students actually are studying mathematics or physics post-16 rather than simply with their stated intention to. This, of course, is to interpret 'participation in post-16 mathematics or physics' in terms of formal school / college participation. We fully accept that other forms of participation occur, for example through hobbies and other manifestations of informal mathematics / physics education, but formal year 12 study in mathematics or physics is a very good proxy for a high level of participation. Further, in the UK Higher Education study in mathematics or physics requires such study (unlike certain other subjects, e.g. philosophy, psychology).

\section{Strand 2: Investigating subjectivities and school culture}

The purpose of the Strand 2 schedule is to explore students' perceptions, feelings and intentions towards physics and mathematics and to see whether what they vocalise is impacted by a range of possible factors. Such factors include school-based issues, engagement with activities, influence from outside of school, structural issues around lessons, relevance of the subjects and intentions about the future. We used the subject of English and their stated favourite subject as comparisons against what was stated about physics and mathematics. In addition we employed the use of metaphors in order to get at students' associations (conscious or unconscious) with physics, mathematics, English and their favourite subjects.

Our interviewing draws on the approaches used by Reiss (2000), Cleaves (2005) and Mendick (2006) so as both to obtain a range of factual material and to uncover student subjectivities. Semi-structured interviewing allows us to cover certain core questions with all interviewees (exploring, for example, student views of the role of parents and other significant adults, peers, teachers and out-of-school experiences on subject choice; student understandings of the nature of mathematics and physics and, as a comparison, English; student views of their abilities in mathematics, physics and English and their relationships to the subjects) while giving opportunities 
to the interviewee to address issues not raised by the interviewer. Figure 3 presents our interview schedule for the first phase.

In Strand 2, 'Investigating subjectivities and school culture', we are working with 12 of our Strand 1 schools in more depth. Our focus is on students of above average attainment in one or both of mathematics and science, since high attainment in these subjects is already known to correlate with greater levels of post-16 participation in mathematics or physics (Smithers \& Robinson, 2005; Matthews \& Pepper, 2007), although many high attaining students in mathematics or physics do not continue with these subjects post16. In each school our original intention was to work with approximately six students, ideally: one girl and one boy who intend to study mathematics and / or physics post-16; one girl and one boy who are undecided; one girl and one boy who intend not to study mathematics and / or physics post-16. Each of these 72 students would be individually interviewed three times - at ages 15, 16 and 17 - on each occasion for typically 25 to 35 minutes.

As with Strand 1 schools, we faced issues of recruitment. Our first set of invitations to 40 schools resulted in the recruitment of only four schools. In the end, our final sample of 12 schools was achieved after four rounds of recruitment, which also included replacing four schools that had initially agreed to participate but then decided, typically only after several months, not to continue (fortunately in all cases before student interviews had been undertaken). The four schools that dropped out did so for a range of reasons: someone at the school had agreed to participate without seeking necessary approval; the school realised they had taken on too many commitments; the school had not appreciated what participation in Strand 2 entailed; and one school failed to give a reason and simply stopped responding to the project.

Thee pilot rounds of design and refinement of our Strand 2 interview schedules were undertaken before the first phase of interviewing took place. In the first phase we conducted interviews with 10015 year-old students against our target of 72 students and in the second phase with 83 of these 100 students, now aged 16. We decided to over-recruit in the first phase to counteract issues to do with attrition resulting from students moving schools, 
students or schools withdrawing consent for subsequent phases and possible difficulties in tracing students post-16 (i.e. in the third phase of interviewing).

At the end of our first phase interviews we devised an interview schedule based on findings from these interviews and initial findings from Strand 1. This went through two rounds of piloting and has now been used in the second phase of Strand 2. In our first phase, we wanted to explore the students' activities and their relationships with their teachers, friends and parents. In addition, since the students were selected on the basis of their intentions and perceived ability in either physics or mathematics, as indicated on the Strand 1 questionnaires, one of our aims was to explore how these correspond to their responses in interview. In the second phase, the focus was on any changes that might have occurred since the first phase interviews were conducted. In the third phase we will explore whether differences between males and females in participation and/or attitudes to post-16 education/careers in mathematics/physics are to do with societal representations of the sexes (e.g. in the media). We will also ask students to be more explicit about their relationships with mathematics/physics and we will do this by exploring their early memories. Finally, we would like students to think about the broader picture as well as themselves and talk about the role they see mathematics/physics playing in decades or centuries to come.

Strand 2 also contains an ethnographic component consisting of observations of classroom or out-of-classroom activities including activities identified from the Strand 2 interviews or the analyses in Strand 1 as being potentially significant in terms of post-16 participation in mathematics or physics. In each school we are observing over the three phases of interviewing lessons and out-of-classroom activities (e.g. science clubs, visits and department meetings) in mathematics and in physics. Rather than using a fixed observation schedule we have so far been using a more open approach based on those factors identified in the literature (e.g. Hollins et al., 2006; Kyriacou \& Goulding, 2006) as being of potential significance (including type of questioning by the teacher, extent of student collaboration, use of language, degree of student autonomy, use of textbooks, seating and other working arrangements). While each of these factors has been the focus of 
many research studies, our overall presumption is that it is factors that relate to how students learn and feel about mathematics and physics that are likely to be most important and so worthy of particular study.

The approach that has underpinned the ethnographic work in Strand 2 to date has therefore been somewhat intuitive and open-ended. The final (third) phase of ethnography will use a deliberate inquiry process guided by triangulating data to develop hypotheses and arrive at research questions using the following:

i. What we have learnt about the Strand 2 schools to date in the ethnographic work;

ii. Analysis from the Strand 1 findings which will entail:

- Comparative analysis of each of the 12 Strand 2 schools using data from their Strand 1 school questionnaires (both mathematics and physics);

- An examination of the Strand 1 responses given by each of the Strand 2 interviewees.

This will allow the final phase of ethnographic work to use a research instrument that has over-arching questions (to be addressed in all Strand 2 schools) along with situationally-appropriate questions specific to each Strand 2 school.

\section{Strand 3: Documenting the reasons for HE choices}

In Strand 3, 'Documenting the reasons for HE (Higher Education) choices', we are working with first year undergraduates since by then they have made their subject or initial career choices and we wanted to know what factors influenced these choices. We intended to recruit 50 students under the age of 21 across four Higher Education Institutions. Half these students would have started first degree courses in accountancy, mathematics, engineering or physics, and half would have started other degrees yet have qualifications 
that would have allowed them to start accountancy, mathematics, engineering or physics courses. Our recruitment went encouragingly to plan. Four very different higher education institutions in England (in terms of their 'status' and the level of qualifications students require to gain access to them) agreed to work with us and we had no difficulty in recruiting undergraduates, 51 of whom we interviewed, who were studying the courses we wished.

We were aiming to capture students' accounts, through interviews typically lasting about 60 minutes, of their affective reactions to both mathematics and physics, allowing us to see whether their identities of mid-adolescence have adapted, or not, to participate in mathematics or physics (cf. Rodd \& Bartholomew, 2006). We expected that these interviews would result in 'narratives of choice' - personalised accounts of how choices seem to have been presented to the students (by parents, by career advisers and by others) - and examples of serendipitous events or critical incidents that seemed to the students to have influenced their decision-making. This would allow us to probe our Strand 1 and Strand 2 conclusions with regard to what makes for effective interventions intended to increase uptake in mathematics and/or physics. More generally, we anticipated that the analysis of student and school factors from Stand 1 would provide a lens that could be used to interrogate Strand 2 and 3 data, to pull out similarities and differences between mathematics and physics participation, thus testing the robustness of the findings.

We decided to interview our Strand 3 undergraduates (typically 18,19 or 20 year-olds) differently from the school students in Strand 2. All the undergraduates knew before the interview was that we were interested in why they had chosen the course that they had chosen. We eschewed an interview schedule, instead conducting what the literature generally refers to as 'narrative interviews' (Hollway \& Jefferson, 2000; Andrews et al., 2008; Chase 2008) where we simply explored with the interviewees large areas such as their education, their family and occasions on which they felt they had made a decision about their future. 
Part of our thinking for using narrative interviews was that the students might well come with quite 'prepared' answers if we simply asked them direct questions such as 'Why are you studying $X /$ not studying $Y$ at university?'. We wanted, in so far as one can in a single interview of about 60-75 minutes, to strike up a relationship with the student we were interviewing, at least to the extent that they relaxed and, in the way beloved of psychoanalysts and psychotherapists, sometimes said the first thing that came into their minds. Of course, the interviews were neither psychoanalytical nor psychotherapeutic sessions, and none of us has formal qualifications in either of these disciplines. Nevertheless, within the team one of us (Rodd) had had prior experience of interviewing in this very open-ended manner (Rodd \& Bartholomew, 2006) and this team member led this strand, undertook about half the total number of interviews and provided training to the other team members who did the other interviews.

Every interviewer wants their interviewees to relax and produce 'authentic data'. We intended to go further than is often the case, e.g. in semi-structured interviewing, in a number of respects. For a start, we wanted to give our interviewees control not only over what they said but the order in which they said it - what is said first and what is said last in a conversation often has particular significance as every counsellor (Kennedy \& Charles, 1990), and most of the rest of us, knows. Furthermore, by following where the interviewee led, rather than feeling that we needed to return to a schedule, we anticipated allowing the interview to wander where it would, possibly into areas we had not anticipated. We wanted to remain open to the possibility that things would bubble up in the interview that the interviewee had not expected.

Four pilot interviews were undertaken and while these helped improve the quality of our interviewing, it was felt that no fundamental changes to our approach were needed. Nevertheless, and in part to ensure a certain comparability between interviewers, we did use the interview guide presented in Figure 4 though it needs to be emphasised that Figure 4 simply indicates the areas to be covered; no attempt was made to use the same form of words for different interviewees. 


\section{Approaches to analysis}

We are currently at various stages in the analysis of the data from our three strands. At this point in the project the analysis is proceeding separately for each strand and for this reason the three strands are discussed separately below, though, as indicated above, findings from each strand are increasingly informing the instruments used in other strands.

\section{Strand 1: Mapping trajectories of engagement and disenchantment}

Our analysis of Strand 1 is being undertaken using multilevel modelling. Multilevel modelling has existed for many decades but its use has taken off in education in the last 20 years or so partly because of the increasing availability of computing power and (fairly) easy to use multilevel modelling software (notably MLwiN, 2009) and partly because the approach has successfully been used in a number of large and influential studies (e.g. Gray et al., 2004, Goldstein et al., 2007; Sammons et al., 2007).

Multilevel modelling can be conceptualised as a particular instance of multiple analysis of variance in which certain restrictions are placed, in advance of the analysis, on the organisation of the dependent variables (in this it differs from factor analysis and principal component analysis). In the paradigmatic case in education, features of individual students (e.g. attainment) are seen as resulting from a hierarchy of effects beginning at the individual student level and then scaling up through successive rungs of a hierarchy, e.g. student class, student school, school area. In the case of UPMAP the lowest (most fine-grained) level of the hierarchy is the individual student, a level that includes effects due to their family since we have insufficient data (i.e. data from sibs) to separate individual and family effects. The next level is class / teacher; the next is school and, in principle (though we only have 141 schools), the next is region of the UK (e.g. Northern Ireland, Scotland, Wales and the nine official government 'regions' within England). 
In the absence of experimentation (e.g. as provided by randomised controlled trials) multilevel modelling, of course, provides evidence for causation through correlations whose likely importance is indicated by effect sizes, quantification of interactions and by the extent to which emerging conclusions fit into (or extend) well-grounded theories. Recent developments allow for nonparametric as well as parametric modelling, non-linearity and the use of repeated measures (longitudinal data).

For UPMAP we drew for our student questionnaires on the existing literature, our own hypotheses and successive rounds of piloting to derive the constructs listed in Table 1. Other student level data available to us (provided by the DCSF from the National Pupil Database, collected via the Pupil Level Annual School Census (PLASC)) in addition to those from the student questionnaires include attainment in national tests at age 11 (key stage 2) and 14 (key stage 3 ), ethnicity and free school meal status (a coarse, dichotomous, measure of socio-economic status).

We are in the process of developing our school level measures based on our school questionnaire returns and other data including school inspection reports from Ofsted (Office for Standards in Education). These measures are likely to include: school type; school resources (number of specialist teachers, etc.); school ethos; leadership; and engagement in school mathematics / physics activities.

Even before we have our second phase of Strand 1 data we will be able, therefore, to answer a large number of specific research questions, for example:

- How does performance in the conceptual tasks relate to intention to participate post- 16 in mathematics / physics?

- What is the relationship between intention to participate post-16 in mathematics / physics and students' descriptions of their confidence when undertaking the conceptual tasks? How does this relate to gender, socio-economic status, prior attainment, etc.? 
- How do such psychological constructs as self-concept, extroversion, internality, emotional stability and competitiveness relate to intention to participate post-16 in mathematics / physics? Are such psychological characteristics of students more or less important than the influences of their school and peers?

- What is the relationship between classroom culture and intention to participate? Is classroom culture more important for certain student groups?

- How do family influences (e.g. parental relationships, home support) relate to intention to participate post-16 in mathematics / physics?

- What can we learn from outlier schools? Studies within school effectiveness research often focus on schools that are positive outliers. Within this research we will also look at schools that are negative outliers, i.e. schools that have lower than expected rates of post-16 participation in mathematics / physics once various 'obvious' correlates (e.g. gender and prior attainment) have been accounted for statistically.

\section{Strand 2: Investigating subjectivities and school culture}

Our Strand 2 analysis is at an earlier stage than is the case for Strands 1 and 3. We are in the process of using NVivo to code our 100 first phase transcribed student interviews. Table 2 presents the outline coding system we are using. Of course, each entry in Table 2 has multiple sub-codings. Our NVivo coding provides us with one type of analysis - namely at the student level.

We anticipate being able to combine this with analysis of our ethnographic findings, with analysis of the Strand 1 findings for these 12 schools and with analyses of our second phase and third phase findings in this strand. Aside from the obvious point that this longitudinal element allows us both to establish continuities and discontinuities over time, successive interviews with students as they age allow the interviewer to go into certain aspects in more 
depth. We are increasingly exploring with students our hypotheses about what, at both the student and the school level, tends to enhance post-16 participation rates in mathematics and physics. We are, after all, keen that our work will have policy implications though we are very open at present as to the audiences, including national government, school head teachers, school classroom teachers and those providing out-of-school experience in mathematics or physics.

\section{Strand 3: Documenting the reasons for HE choices}

There is a long history of using interviews in educational research. Perhaps because talking with people is such a natural human activity, theorising interviewing as a research method has only really taken off in the last two decades or so. A classic study was that of Briggs (1986) who argued that "interview techniques are prima facie expressions of our underlying, generally unstated theories of communication and of reality" (p. 115) while Mishler in the same year "found that under many different interviewing conditions [respondents'] accounts often resemble stories, that is, they display narrative features" (Mishler, 1996, p. 138).

The narrative approach to interviewing that we used drew particularly upon Hollway and Jefferson (2000). In that study, Hollway and Jefferson were interested to uncover people's fears about crime. During their piloting they became increasingly dissatisfied with a 'traditional' approach to interviewing and came, instead, to develop what they term "our free-association narrative interview" (p. 39). Here, the aim is to produce what they term 'an emerging Gestalt, i.e. a picture in which the whole is greater than the sum of its parts. In terms of how our interviews are being analysed, we have adopted the approach of Hollway and Jefferson (2000) in which respondents are seen as 'defended subjects'. 'Defence' here is used as in the psychoanalytical (particularly Kleinian) sense in which we all employ defences against our anxieties and fears (and there is a large existential literature on defence against anxiety informed by Heidegger, Kierkegaard, Sartre and others). 
Adopting an approach that begins with defence against anxiety made clear sense in Hollway and Jefferson's study since they were explicitly investigating people's fears about crime. The approach is appropriate in Strand 3 of our study too as we are interested in why certain undergraduates did not continue with mathematics or physics, including cases where they had the qualifications that would have enabled them so to continue. In this we are following in the footsteps of Nimier (1993) who, in a paper titled 'Defence mechanisms against mathematics' explored the extent to which students' attitudes towards mathematics might represent unconscious defences against it.

\section{Discussion}

Overall, our approach is manifestly one of mixed methods in the sense that the term is usually understood (Sammons, in press) in that we use a range of research instruments and analytical approaches. At the same time, we do not wish to defend our approach, which some might see as eclectic, purely on grounds of pragmatism (a fairly routine justification for mixed methods, perhaps partly as an attempt to sidestep apparently never-ending debates within education research over positivism, post-positivism, interpretivism and post-modernism). Our work is rooted in an epistemology that takes seriously our participants' perceptions of 'realities' (as revealed in interview and questionnaire responses), our own descriptions of 'realities' (as revealed by our ethnographies and interpretations of interviews and questionnaires) and 'objective' data about such matters as attainment, subject choice and family circumstances without either privileging any one of these or presuming that any one is the royal road to truth.

Recent research into the reasons why students do or do not choose to study mathematics or science, once they get the choice, is increasingly focusing on issues to do with student identity. For example, Taconis \& Kessle (2009, p. 1115) proposed "that the unpopularity of science in many industrialised countries is largely due to the gap between the subculture of science, on the one hand, and students' self image, on the other". They undertook a study 
with Dutch ninth-grade students and found that "Dutch students see typical peers who favour science subjects (physics/biology) as less attractive, less popular and socially competent, less creative and emotional, and more intelligent and motivated than typical peers who favour humanities subjects (economics/languages)" (p. 1128), a similar finding to an earlier one in Germany (Hannover \& Kessels, 2004). Such studies encourage us in our assertion that issues of student identity need to be considered when attempting to understand issues of student participation and subject choice.

Concurrently, a number of studies have looked at reasons why young women may be less likely to take mathematics and physics once they become optional. While there seem, at least as yet, to be no simple answers, a number of researchers have concluded that anxiety and lack of confidence and enjoyment in mathematics or physics are especially important for young women (Boaler, 1997; Walkerdine, 1998; Murphy \& Whitelegg, 2006; Cann, 2009). Concurrently, notions of 'identity' have increasingly been used in both mathematics and science education. In both disciplines it is though acknowledged that the term is used in a range of ways (Shanahan, 2009; Valero, 2009) with key issues being the extent to which a person's identity is seen as fixed, situated or fluid and the extent to which identity is affected by social structures.

We are attracted by the notion of identity as an explicans of subject choice but wish to see this as one level in a hierarchy that goes from the unconscious forces that operate within each of us to structural forces that operate at national level. Does anyone (even rational choice theorists - cf. Sullivan (2006)) really suppose that all (perhaps even most) important decisions, including those about which subjects one studies, are made only consciously and rationally? Our expectation is that UPMAP will achieve two main aims: first, to provide a better understanding, including where possible a quantitative understanding, of the relative importance of these forces; secondly, that it will provide evidence to suggest where targeted interventions aimed at increasing uptake in mathematics and physics might most effectively be tried. 


\section{Conclusion}

The synthesised findings from the three strands of the UPMAP project will allow us to identify and interpret the range of factors, their relative importance and their interactions that influence post-16 participation in mathematics and in physics. This will provide us with a strong evidence base upon which to make recommendations about the kinds of interventions, initiatives and practices that are likely to have the greatest impact on different student groups and students' developing identities, and thus in raising participation and engagement in post-compulsory mathematics and physics.

By employing both extensive quantitative and fine-grained qualitative methods we anticipate being able to generate robust and replicable findings that are sensitive to differences between students and between schools. By studying both mathematics and physics we envisage the production of new knowledge about the approaches needed to tackle the related yet distinct problems of engagement and post-16 under-participation in these two subjects.

\section{Acknowledgements}

We are very grateful to the many students, teachers and schools for participating in this work, to the Economic and Social Research Council for funding the research (Grant RES-179-25-0013), to the DCSF for providing data, to Anna Sfard for extensive discussion and to anonymous reviewers for valuable comments.

\section{References}

Andrews, M., Squire, C. \& Tamboukou, M. (Eds.). (2008). Doing narrative research. Los Angeles, CA: Sage.

Black, L., Mendick, H. \& Solomon, Y. (Eds.). (2009). Mathematical relationships in education: Identities and participation. London: Routledge. 
Blalock, C.L., Lichtenstein, M.J., Owen, S., Pruski, L., Marshall, C. \& Toepperwein, M. (2008). In pursuit of validity: a comprehensive review of science attitude instruments 1935-2005. International Journal of Science Education, 30, 961-977.

Blenkinsop, S., McCrone, T., Wade, P. \& Morris, M. (2006). How do young people make choices at 14 and 16? Research Report 773. Nottingham: DfES.

Boaler, J. (1997). Experiencing school mathematics: Teaching styles, sex and setting. Buckingham: Open University Press.

Boaler, J. (2009). The elephant in the classroom: Helping children learn and love maths. London: Souvenir Press.

Briggs, C.L. (1986). Learning to ask: A sociolinguistic appraisal of the role of the interview in social science research. Cambridge: Cambridge University Press.

Brown, M., Brown, P. \& Bibby, T. (2008). "I would rather die": reasons given by 16-year-olds for not continuing their study of mathematics, Research in Mathematics Education, 10, 3-18.

Cann, R. (2009). Girls' participation in post-16 mathematics: a view from pupils in Wales. Gender and Education, 21, 651-669.

Carson, S. (1999). Shaping the future: 2 - physics in mathematical mood. Bristol: Institute of Physics.

Centre for Longitudinal Studies (2010) Cohort Studies. http://www.cls.ioe.ac.uk/ (last accessed 5 December 2010).

Chase, S.E. (2008). Narrative inquiry: multiple lenses, approaches, voices. In N.K. Denzin \& Y.S. Lincoln (Eds.), Collecting and interpreting qualitative materials (pp. 57-94). Los Angeles, CA: Sage.

Cleaves, A. (2005). The formation of science choices in secondary school. International Journal of Science Education, 27, 471-486. 
Gill, T., Vidal Rodeiro, C.L. \& Bell, J.F. (2009). The complexities surrounding the uptake of A-level Physics. Paper presented at the British Educational Research Association Annual Conference, Manchester University, September 2009.

Glenn D.W. \& Jackson, C. (1994). The personality of physicists. Personality and Individual Differences, 16, 187-189.

Goldstein, H., Burgess, S. \& McConell, B. (2007). Modelling the effect of pupil mobility on school differences in educational achievement. Journal of the Royal Statistical Society, Series A, 170, 941-954.

Gray, J., Schagen, I. \& Charles, M. (2004). Tracking pupil progress from Key Stage 1 to Key Stage 2: how much do the 'route' taken and the primary school attended matter? Research Papers in Education, 19, 389-413.

Hannover, B. \& Kessels, U. (2004). Self-to-self prototype matching as a strategy for making academic choices. Why high school students do not like math and science. Learning and Instruction, 14, 51-67.

Harré, R. \& Gillett, G. (1995). The discursive mind. Thousand Oaks, CA: Sage.

Hay, I. \& Ashman, A.F. (2003) The development of adolescents' emotional stability and general self-concept: the interplay of parents, peers, and gender. International Journal of Disability, Development and Education, 50, 77-91.

Hollins, M., Murphy, P., Ponchaud, B. \& Whitelegg, E. (2006) Girls in the physics classroom: A teachers' guide for action. London: Institute of Physics.

Hollway, W. \& Jefferson, T. (2000). Doing qualitative research differently: Free association, narrative and the interview method. London: Sage.

Institute For Social \& Economic Research (2010) The UK Longitudinal Studies Centre. http://www.iser.essex.ac.uk/survey/ulsc (last accessed 5 December 2010). 
Kenedy, E. \& Charles, S. C. (1990). On Becoming a Counsellor, $2^{\text {nd }}$ edn. Dublin: Gill and Macmillan.

Kyriacou, C. \& Goulding, M. (2006). A systematic review of strategies to raise pupils' motivational effort in Key Stage 4 Mathematics. Report. In: Research Evidence in Education Library. London: EPPI-Centre, Social Science Research Unit, Institute of Education, University of London.

Lord, P. \& Jones, M. (2006). Pupils' experiences and perspectives of the National Curriculum and assessment: Final report for the research review. Slough, UK: NFER.

Marsh, H.W. (1992). Self Description Questionnaire (SDQ) II: A theoretical and empirical basis for the measurement of multiple dimensions of adolescent self-concept. A test manual and research monograph. Macarthur, New South Wales, Australia: University of Western Sydney, Faculty of Education.

Matthews A. \& Pepper, D. (2007). Evaluation of participation in A level mathematics: Final report. London: Qualifications and Curriculum Agency.

Mendick, H. (2006). Masculinities in mathematics. Maidenhead, UK: Open University Press.

Mishler, E.G. (1986). Research interviewing: Context and narrative. Cambridge, MA: Harvard University Press.

MLwiN (2009). MLwiN: A software package for fitting multilevel models. Bristol: Centre for Multilevel Modelling, University of Bristol. http://www.cmm.bristol.ac.uk/MLwiN/index.shtml (last accessed 31 December 2009).

Murphy, P. \& Whitelegg, E. (2006). Girls in the physics classroom: A review of the research on the participation of girls in physics. London: Institute of Physics.

Nardi, E. \& Steward, S. (2003). Is mathematics T.I.R.E.D? A profile of quiet disaffection in the secondary mathematics classroom. British Educational 
Research Journal, 29, 345-366.

Nimier, J. (1993) Defence mechanisms against mathematics. For the Learning of Mathematics, 13, 30-34.

Osborne, J., Simon, S. \& Collins, S. (2003). Attitudes towards science: a review of the literature and its implications. International Journal of Science Education, 25, 1049-1079.

QCA Research Faculty (2007). Evaluation of participation in GCE mathematics: Final report, QCA/07/3388. London: QCA. Available at http://www.ofqual.gov.uk/files/QCA 3388 Maths GCE eval report.pdf (last accessed 30 December 2009).

Reiss, M.J. (2000). Understanding science lessons: Five years of science teaching. Buckingham, UK: Open University Press.

Reiss, M.J. (2005). The importance of affect in science education. In S. Alsop (Ed.), Beyond Cartesian Dualism: Encountering affect in the teaching and learning of science (pp. 17-25). Dordrecht: Kluwer.

Rodd, M. \& Bartholomew, H. (2006). Invisible and special: young women's experiences as undergraduate mathematics students. Gender \& Education, $18,35-50$.

Royal Society (2007) The UK's Science and Mathematics Teaching Workforce. London: Royal Society. Available at http://royalsociety.org/uploadedFiles/Royal Society Content/Influencing $P$ olicy/Education/Reports/SNR1 full report.pdf(last accessed 15 July 2010).

Sammons, P. (in press). The contribution of mixed methods to recent research on educational effectiveness. In A. Tashakkori \& C. Teddlie (Eds.), Handbook of Mixed Methods Research, $2^{\text {nd }}$ edition. Los Angeles, CA: Sage.

Sammons, P., Day, C., Kington, A., Gu, Q., Stobart, G. \& Smees, R. (2007). Exploring variations in teachers' work, lives and their effects on students: key findings and implications from a longitudinal mixed methods study. British Educational Research Journal, 33, 681-701. 
Schreiner, C. (2006). Exploring a ROSE-garden: Norwegian youth's orientations towards science - seen as signs of late modern identities. Oslo: Faculty of Education, University of Oslo.

Sfard, A. \& Prusak, A. (2005). Telling identities: in search of an analytic tool for investigating learning as a culturally shaped activity. Educational Researcher, 34, 14-22.

Shanahan, M.-C. (2009). Identity in science learning: exploring the attention given to agency and structure in studies of identity. Studies in Science Education, 45, 43-64.

Smithers, A. \& Robinson, P. (2005). Physics in schools and colleges: Teacher deployment and student outcomes. Buckingham: The Carmichael Press.

Sullivan, A. (2006). Students as rational decision-makers: the question of beliefs and attitudes. London Review of Education, 4, 271-290.

Taconis, R. \& Kessels, U. (2009). How choosing science depends on students' individual fit to 'science culture'. International Journal of Science Education, 31, 1115-1132.

UPMAP (2009). Home page. http://www.ioe.ac.uk/study/departments/gems/4814.html (last accessed 13 December 2009).

Valero, P. (2009). In L. Black, H. Mendick \& Y. Solomon (Eds.), Mathematical relationships in education: Identities and participation (pp. 213-226). London: Routledge.

Walkerdine, V. (1998). Counting girls out: Girls and mathematics. London: Falmer Press.

Williams, P. (2008). Independent review of mathematics teaching in early years settings and primary schools: Final report. London: DCSF. Available at

http://publications.teachernet.gov.uk/eOrderingDownload/Williams\%20Mat hematics.pdf (last accessed 30 December 2009). 
Figure 1

One of the mathematics conceptual tasks used in the year 8 mathematics questionnaire.

\section{MATHEMATICS TASKS}

These tasks have nothing to do with your school marks and your answers will not be seen by your teachers or anyone else at your school. We simply would like to compare your answers to these task items with your attitudes to mathematics.

\section{T1. TILES}

Raj has some white square tiles and some grey square tiles.

They are all the same size.

She makes a row of six white tiles.

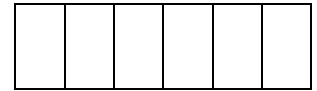

She surrounds the white tiles with a single layer of grey tiles.

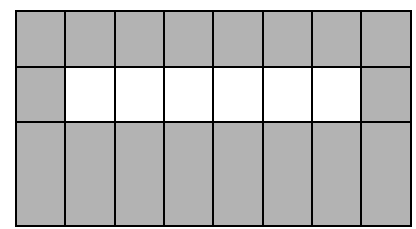

Then she makes a row of twelve white tiles.

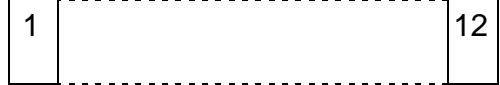

And then she surrounds these white tiles with grey tiles.

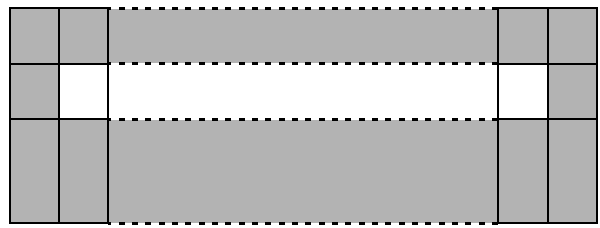

a) How many grey tiles does she use to surround a row of 12 white tiles?

Show your working here: 
b) How many grey tiles does she need to surround a row of 60 white tiles?

Show your working here:

c) How confident are you that your answer to part (b) is correct?

Very confident $\square \quad$ Fairly confident $\square \quad$ Not confident $\square \quad$ Just guessing

d) Write a rule for the number of grey tiles needed to surround a row of $n$ white tiles. You can write a sentence or use algebra.

d) How confident are you that your answer to part (d) is correct? Very confident

Fairly confident

Not confident

Just guessing

\section{T2. How much do you agree with the following statements?}

\section{I find doing 'find the pattern' problems:}

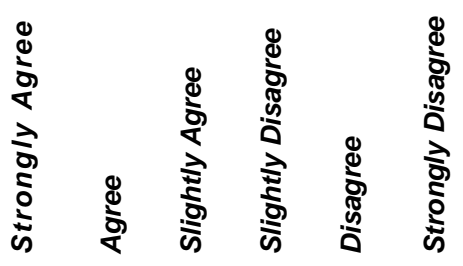
a) Enjoyable
b) Easy
c) Interesting 
Figure 2

The two electricity conceptual tasks used in the year 10 physics questionnaire. Tasks kindly provided by Professor Robin Millar, University of York, UK.

\section{PHYSICS TASKS}

These tasks have nothing to do with your school marks and your answers will not be seen by your teachers or anyone else at your school. We simply would like to compare your answers to these task items with your attitudes to physics.

\section{E1. ELECTRICITY 1}

In this circuit below, the reading on ammeter $A_{1}$ is 0.4 amps.

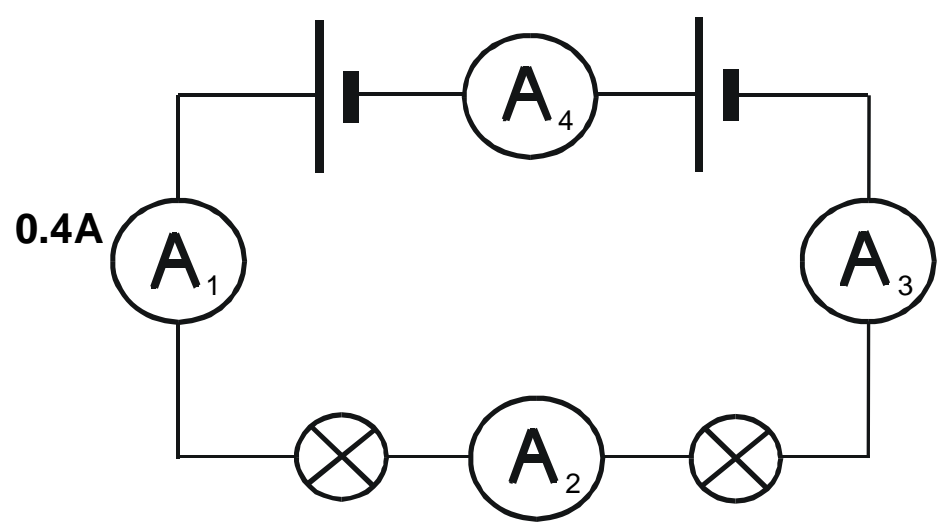

What reading you would expect to see ....
(a) .. on ammeter $\mathrm{A}_{2}$ ?
(b) .. on ammeter $A_{3}$ ?
(c) .. on ammeter $\mathrm{A}_{4}$ ?

Put a cross $\searrow$ in ONE box Put a cross $\searrow$ in ONE box Put a cross $\searrow$ in ONE box
$\square$ More than $0.4 \mathrm{~A}$
More than $0.4 \mathrm{~A}$
More than $0.4 \mathrm{~A}$ 
$\square$ Exactly $0.4 \mathrm{~A}$

Less than $0.4 \mathrm{~A}$, but

not zero

Zero $\square$ Exactly $0.4 \mathrm{~A}$

Less than $0.4 \mathrm{~A}$, but

not zero

Zero $\square$ Exactly $0.4 \mathrm{~A}$

Less than $0.4 \mathrm{~A}$, but not zero

Zero

(d) Put a cross $\chi$ in ONE box below to explain your reason for choosing these answers.

$\square$ The current is the same all round the circuit.

Each bulb uses up some of the current, leaving less for the next one.

The first bulb uses up all of the current.

The current is large close to the battery, and smaller further away.

The reading is biggest where the currents from the two ends of the battery meet.

(e) How confident are you that your answers to question E1 are correct?

Very confident $\quad \square \quad$ Fairly confident $\quad \square \quad$ Not confident $\quad \square \quad$ Just guessing 


\section{E2. ELECTRICITY 2}

A bulb is connected to a battery.

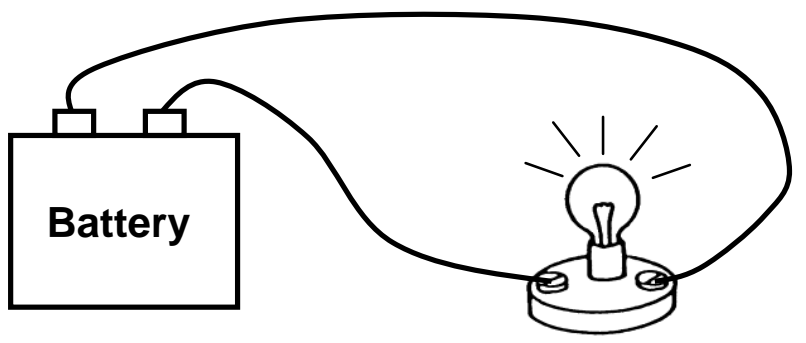

The bulb is lit.

(a) Which of the following best describes the electric current in this circuit?

Put a cross $X$ in ONE box only.

There is an electric current through one wire to the bulb. It is all used up in the bulb. So there is no current in the other wire.

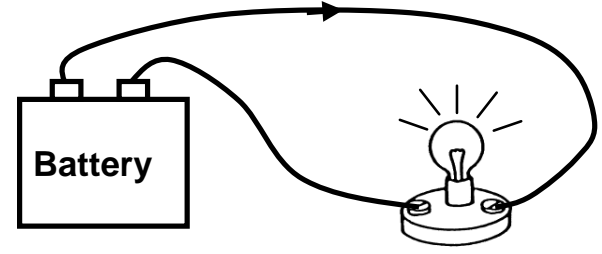

There is an electric current through one wire to the bulb. Some of it is used up in the bulb. So there is a smaller current in the other wire.

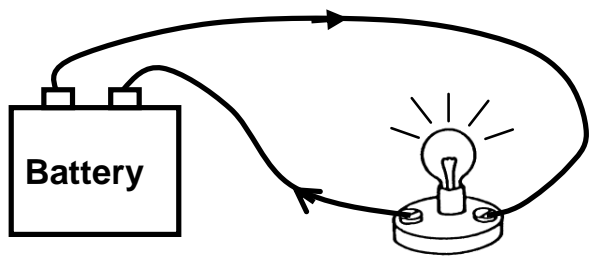

There is an electric current through one wire to the bulb. It passes through the bulb and back to the battery. The current in the other wire is the same size.

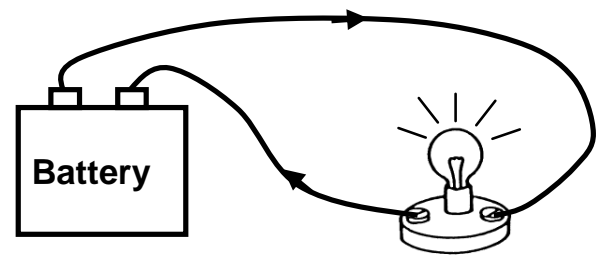

There are two electric currents from the battery to the bulb. They meet at the bulb and this is what makes it light.

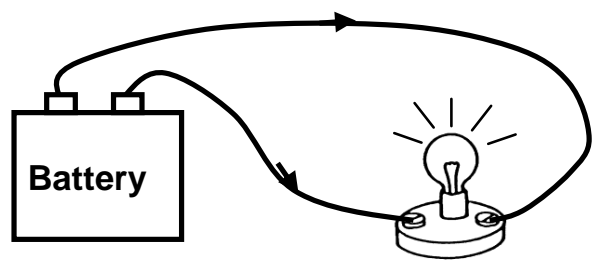


(b) How confident are you that your answer to part (a) is correct?

Very confident $\square \quad$ Fairly confident $\square \quad$ Not confident $\square \quad$ Just guessing $\square$

\section{E3. How much do you agree with the following statements?}

I find doing 'electricity' problems:

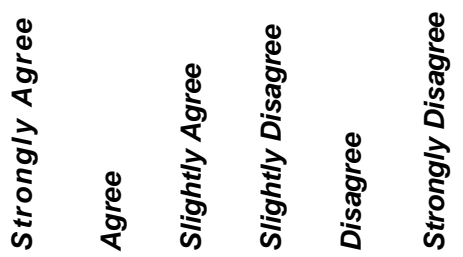
a) Enjoyable
b) Easy
c) Interesting 
Figure 3

Strand 2 interview schedule in the first phase.

1. Could you please tell me about yourself as a person?

2. Could you please tell me about yourself as

i. A student in this school? [Try to get a feel for involvement in activities / engagement with school / teachers / how they fit in with peers both academically \& socially]

ii. As a person outside of school? [Ask about friends / outside school activities / interests]

3. What will you be doing after your GCSEs? [Prod for reasons why or why not physics \& maths chosen and why or why not other subjects chosen]

4. And how does your family / teachers/friends feel about this?

5. Tell me a little about your family? [ Try to get a feel for family structure / parental education / family influences]

i. Do you feel they have in anyway influenced your subject choices?

6. What are your favourite subjects? [Find out why, intrinsic / extrinsic reasons. Prompt for comparisons with maths / physics.]

7. Think of how you are doing in your other subjects. Where does maths fit in with how you are within your subjects at school? [Repeat question for physics]

8. How do you feel about maths? [Repeat question for physics. Additional prompt: pick up on words used for both subjects and ask a question that tries to tease the interaction between both.]

9. What was your most memorable maths lesson? Why? [Repeat question for physics. Additional prompt: pick up on words used for both subjects and ask a question that tries to tease the interaction between both.]

10. What is your typical maths lesson like? [Repeat question for physics. Additional prompt 1: pick up on words used for both subjects and ask a question that tries to tease the interaction between both. Additional 
prompt 2: be aware of issues like peer group interaction, relationship with teachers or teaching style that may switch students off a subject.]

11. If you could think of three words that you associate with maths what would they be? [Repeat question for physics, for favourite subject and for English]

12. If maths was an animal which animal would it be? [Repeat question for physics, for favourite subject and for English]

13. Do you feel that maths has a role in your everyday life outside of school? Please give me examples. [Repeat question for physics, for favourite subject and for English]

14. What school subjects do you think will have an important role to play in your future, either in your everyday life, further education or jobs you may be thinking of doing?

15. Do you think maths will have an important role to play in your future, either in your everyday life, further education or jobs you may be thinking of doing? Please give me examples. [Repeat question for physics, for favourite subject and for English]

16. Have you thought about where you would like to be in:

i. 2 years' time? [Explore]

ii. 5 years' time? [Explore]

iii. 10 years' time? [Explore]

\section{Read passage:}

Sam and Alex are school friends. One day, Sam meets Alex outside the library.

Alex says, "Hi Sam. What are you up to?"

Sam replies, "Oh, I was just looking at what I might do after my GCSEs."

Alex says, "Have you decided anything?"

Sam replies, "Yeah, I've decided to take A Level maths."

i. What do you think of Sam? [Explore]

Sam and Alex meet at a school reunion ten years later.

Alex says, "Hi Sam. What have you been up to since we last met?"

Sam replies, "Well, I graduated with a degree in mathematics and have been working as a mathematician since then." 
ii. What do you think Sam's life is like? [Explore]

18. Is there anything that you think I should have asked that might help us find out more about what influences young people's subject choices? 
Figure 4

Strand 3 interview guide.

Part 1: So please tell me about you education. You can start anywhere you like.

Follow ups

1. Please tell me more about your primary/secondary school.

2. How was transferring to secondary school for you?

3. Please tell me about transferring to post-16 studies.

4. Did your secondary school help?

5. Same or different institution?

6. Tell me about your subject choices for A-Level.

Part 2: Please tell me about your family and how you feel they have been involved in your education.

Follow ups

1. Any role models or people that put you off?

2. Culture.

3. Wider notion of family / community.

4. Have you ever been involved with sport / music / drama / volunteering / religious activities?

Part 3: Please tell me about any times or periods where you have felt you have made a decision about your future.

1. Please tell me about any incidents where you have felt a decision about your future has been made on your behalf.

2. Any thoughts about what you will be doing after university?

3. Any reflections on your first term? 


\section{Table 1}

The student questionnaire constructs. For example, the construct 'Emotional stability' measures students' freedom from anxiety and depression (Marsh, 1992). We were interested in this construct for two reasons. First, there is a reciprocal relationship between the general self-concept and emotional stability (Hay \& Ashman, 2003); We wondered if this was the case for either or both of mathematics- and physics-specific self-concept. Secondly, there is evidence that students who enter higher education from less represented groups (e.g. Black, low SES males) are more likely to end up with depression. We wanted to explore issues around emotional stability, intention to participate and less represented groups. To give a second example, studies have suggested a relationship between where one is on a scale of introversion-extraversion and the likelihood of one choosing a science-based career; for instance, introversion has been found to be more common amongst physicists (Glenn \& Jackson, 1994). We felt that exploring possible relationships between this trait and students' attitudes and intentions might expose patterns that could inform possible interventions.

\section{Construct} Number of items

Self concept 12

Advice pressure to study

Intrinsic value

Extrinsic value

Attitude to and perceptions of maths/physics lessons

Perception of teachers

Sense of school belonging

Emotional stability

Competitiveness

Introversion

Home support for achievement 8

Home support for achievement in general 3

$\begin{array}{ll}\text { Relationship with parents } & 4\end{array}$

$\begin{array}{ll}\text { Engagement with ICT } & 6\end{array}$

$\begin{array}{ll}\text { Social support } & 6\end{array}$

Global motivation and aspiration $\quad 4$ 
Table 2

NVivo coding for the first phase of the Strand 2 student interviews.

\section{STUDENT'S SELF IMAGE}

1. Self-image

\section{STUDENT ACTIVITY}

2. Outside activity

3. Engagement with after school activities

\section{STUDENT'S SOCIAL RELATIONSHIPS}

4. Parental circumstances

5. Parent-student relationship

6. Family influence

7. Social world

8. Maths: Perception of student-teacher relationship

9. Physics: Perception of student-teacher relationship

10. Other subjects (or in general): Perception of student-teacher relationship

11. Maths: Perception of student-student relationship

12. Physics: Perception of student-student relationship

13. Other subjects (or in general): Perception of student-student relationship

\section{SUBJECT PREFERENCES; SUBJECT AND CAREER CHOICES}

14. All subjects: Reasons for choosing preferred subjects

15. Maths: Post-16 choices

16. Physics: Post-16 choices

17. Reasons for not choosing maths

18. Reasons for not choosing physics

19. Higher Education choice 
20. Career choice

STUDENT'S PERCEPTIONS OF SUBJECT, SELF, TEACHER, LESSON

21. Maths: Perception of subject

22. Physics: Perception of subject

23. Other subjects: Perception of subject

24. Academic self-concept

25. Maths self concept

26. Physics self-concept with subject

27. Maths: Teacher influence

28. Physics: Teacher influence

29. Other subject: Teacher influence

30. Maths lesson

31. Physics lesson

32. Other subject

STUDENT'S PROJECTIONS ABOUT THE FUTURE

33. Importance for future

34. Knowledge of courses beyond A level

35. Identity

36. Future plans

37. Sam 